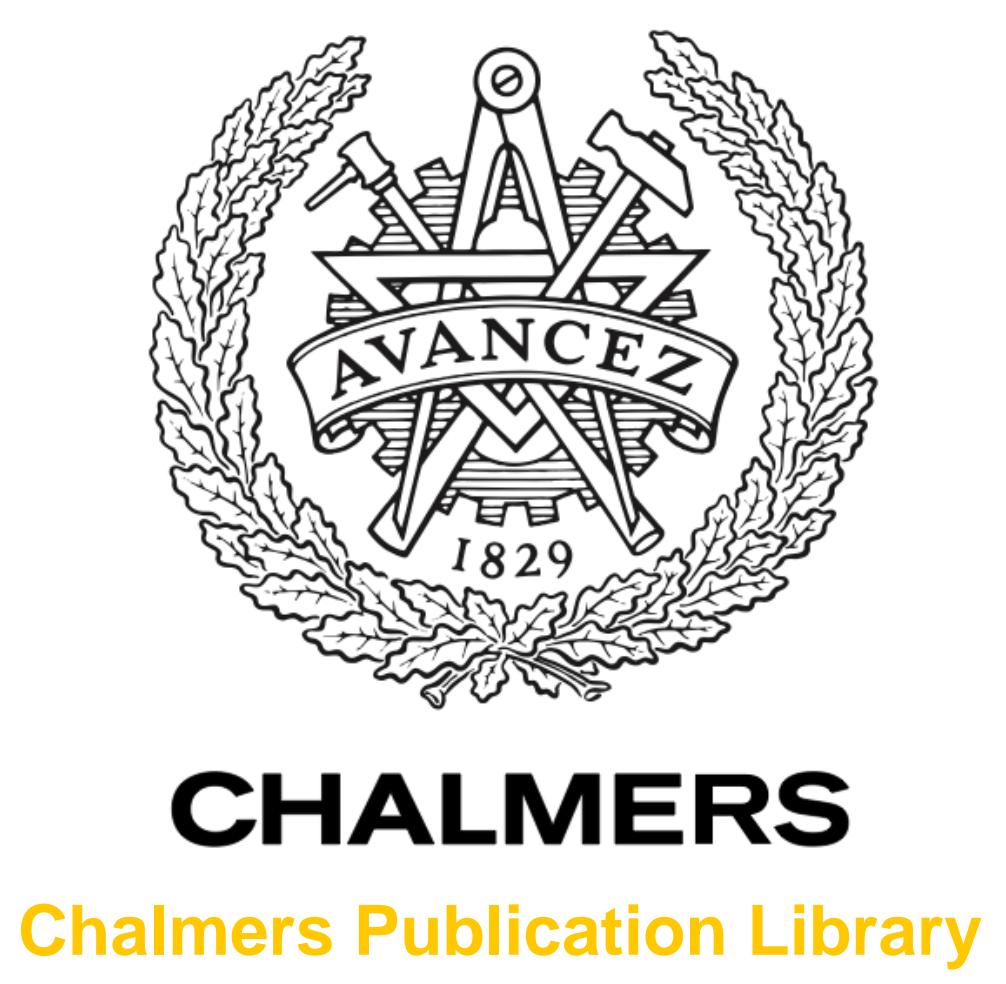

\title{
From job-less growth to growth-with-less-jobs: Employment and equity impact of technical and organisational change
}

This document has been downloaded from Chalmers Publication Library (CPL). It is the author's version of a work that was accepted for publication in:

Science and Public Policy (ISSN: 0302-3427)

Citation for the published paper:

Alänge, S. ; Jacobsson, S. ; Lindberg, P. (1996) "From job-less growth to growth-with-lessjobs: Employment and equity impact of technical and organisational change". Science and Public Policy, vol. 23(1), pp. 27-38.

Downloaded from: http://publications.lib.chalmers.se/publication/179010

Notice: Changes introduced as a result of publishing processes such as copy-editing and formatting may not be reflected in this document. For a definitive version of this work, please refer to the published source. Please note that access to the published version might require a subscription. 


\title{
FROM JOB-LESS-GROWTH TO GROWTH-WITH-LESS-JOBS
}

\author{
Employment and equity impact of \\ technical and organisational change
}

\author{
Sverker Alänge \\ Staffan Jacobsson \\ Per Lindberg
}

School of Technology Management and Economics

Chalmers University of Technology

S-412 96 Göteborg, Sweden 
Sverker Alänge, Staffan Jacobsson and Per Lindberg are at the School of Technology Management and Economics, Chalmers University of Technology, S-412 96

Göteborg, Sweden. Tel: +46 31772 1234; Fax: +46 317721237. 


\begin{abstract}
New technical innovations in the shape of new production technologies are known to affect productivity, but also new organisational innovations and new ways of designing products have now been found to have a profound influence on productivity. These innovations have moved the industrialised countries into a stage where industrial growth is accompanied by a continuous reduction in industrial employment. This development will greatly influence our society and put stringent demands on our political decision making apparatus to avoid that a growth in the 'Wealth of Nations' will not be combined with a growth in poverty.
\end{abstract}




\section{CONTENTS}

Page

1. Introduction 1

2. Growth-with-Less-Jobs in the Industrial Sector 2

3. Technical and organisational Innovations - A Brief Presentation

3.1 New production techniques 5

3.2 New organisational forms 6

3.3 Examples at the firm level 9

3.3.1 Motorola 9

3.3.2 IBM Järfälla 10

3.3.3 Saab Automobile 10

3.4 The uneven international diffusion 11

4. Consequences for Employment - A Discussion 12

5. Conclusions 16

References 17 


\section{INTRODUCTION ${ }^{1}$}

There are widespread expectations that in the present economic recovery industrial employment will increase again and mitigate the severe unemployment problems of the depressed OECD economies. The purpose of this paper is to argue that for the bulk of the OECD countries, the hope is probably futile. Industrial employment will instead, at best, stay at present levels which, of course, means that an expansion of employment opportunities will necessarily have to take place in other sectors; private service sector, public sector or agriculture.

This is not a new proposition. 10-15 years ago, a great deal of work was undertaken to analyse the phenomenon of 'job-less growth' and its consequences (Cooper and Clark 1982, Freeman 1977, Palmer et al. 1984) but the lessons of those studies seemed to have been largely forgotten in the economic boom of the 1980s. One exception is the Chief Executive Officer (CEO) of Asea Brown Boveri, Percy Barnevik, who points to the significant labour displacing effects of new innovations and suggests that industry will most probably, not even in combination with private and public services, be able to create enough new employment. ${ }^{2}$ Instead, Barnevik argues that employment is a political question hinting at solutions such as a 6 hour working day and shared work tasks.

The innovations referred to by Percy Barnevik are not only new technical innovations in the shape of new production technologies but also new organisational innovations and new ways of designing products. From a whole set of case studies, undertaken by ourselves and others, we know that these innovations have a very great rationalisation potential and that they can only strengthen the tendency towards 'job-less growth' discovered at the end of the 1970s.

Indeed, we will argue that we have moved to a stage where industrial growth is accompanied by a continuous reduction in industrial employment. This development will greatly influence the shape of our society and put stringent demands on our political decision making apparatus to avoid that a growth in the "Wealth of Nations" will not be combined with a growth in poverty.

The paper is structured in the following way. In section 2 we will briefly introduce some theoretical and recent empirical relationships between technical change and industrial employment. Section 3 shifts the focus to the level of the firm and we describe the main features of current technical and organisational innovations. A few detailed examples of the implementation of organisational innovations are provided, as well as a discussion of the uneven diffusion of such innovations between Japan, the US and Europe. In section 4 , some main lines of thought as to how to handle a situation with a continuous reduction in industrial employment are discussed. In section 5, the main conclusions are summarised. 


\section{GROWTH-WITH-LESS-JOBS IN THE INDUSTRIAL SECTOR}

From case studies (e.g. those in section 3.3), it is clear that technical/organisational innovations can have a strong labour displacing effect. For example, a rough calculation of the labour displacing effect of numerically controlled machine tools, robots and computer aided design (CAD) in the period 1980-1986 in the OECD countries came to 1.1 million jobs (Metal Trades Committee 1988). It would, however, be highly inappropriate to aggregate the employment displacing effects at the machine level (or at an equivalent level for organisational changes) to higher levels, e.g. the industry level.

Output can be increased so as to compensate for the labour displacing effects of technical change through basically three mechanisms. First, the new production technology needs labour to be produced. The design, production and marketing of the new machines (robots etc.) generate new jobs and from a national perspective, the strength of the backward linkages to the capital goods industry determines the extent of this compensationary mechanism.

Second, if the technical/organisational changes lead to cheaper products, the gains can be passed on to the consumer or, for industrial products, to other firms. This may result in a rise in aggregate (both consumer and investment) demand. Such compensation effects can be expected to go much beyond the sector in which the new technology/organisation is applied. Again, the types and strengths of the inter-sectoral links in a country determine the degree to which the compensation effects stay within the country or are taken abroad.

Third, an increase in the demand for labour may take place due to technical change in the form of new products, as opposed to new processes, which need labour to be produced. For example, electronics is not used only to rationalize production but also to form new products such as VCRs. Indeed, this is perhaps the most central feature of the relationship between technical change and employment; in a process of creative destruction, new technology opens up ${ }^{3}$ hitherto unimagined avenues for investment and employment expansion. ${ }^{4}$

These mechanisms may, or may not, result in a growth in output which compensates for the labour displacing effect of new production technology or new organisational forms. ${ }^{5}$ For the developed countries, taken jointly, Figure 1 and Table 1 depict the empirical relationship between output and employment in the period 1963-1990. Until the end of the 1970 s, there was a slow growth in employment in the manufacturing sector $(10 \%)$; output expanded enough (56\%) to more than compensate for the increases in labour productivity $(41 \%)$. 
Insert Figure 1

Figure 1. Production vs. Employment 1963-1990 in developed countries (Manufacturing sector, ISIC 300)

Source: Elaboration on data supplied by UNIDO 
Since then, however, the relationship between output and employment has changed character, from weakly positive to negative (the line in Figure 1 takes on a 'bananashaped' pattern). As can be seen in Table 1, this is not due to an increase in productivity but is instead due to a decrease in the rate of growth of output (26\%) which is greater than the decrease in the rate of growth of productivity $(33 \%){ }^{6}$

\section{Table 1}

Relationship between changes in manufacturing output and employment in the developed countries 1968-1979 and 1979-1990 (change in the period studied, in \%)

$\begin{array}{llll} & \text { Output } & \text { Employment } & \text { Productivity } \\ 1968-1979 & 55.5 & 10.0 & 41.4 \\ 1979-1990 & 25.7 & -5.8 & 33.3\end{array}$

Source: Elaboration on data supplied by UNIDO

The developed countries have therefore clearly moved from close to a 'job-less growth' in manufacturing in the 1970s towards a 'growth with less jobs' in the 1980s. This process, we would argue, is going to be accentuated in the 1990s.

The reason for our expectations is that industry is introducing new technical and organisational innovations; innovations which have a proven capacity to reduce labour input drastically. Whilst many of these innovations were first introduced in the 1970s, their large scale diffusion, in particular the organisational innovations, is a feature of the 1990 s. With a massive implementation of these innovations, we expect a return to higher growth rates in labour productivity through large scale labour displacement. Unless output expands at a much faster rate than before, this diffusion process will strengthen the trend in the 1980 s. In the next section we will describe these innovations and give examples of their impact. 


\section{TECHNICAL AND ORGANISATIONAL INNOVATIONS - A BRIEF PRESENTATION}

This chapter begins with a brief presentation of technical and organisational innovations which have begun to be diffused in industry, although to a varying extent. The presentation is brief since there is an extensive literature covering the area (e.g. Edquist and Jacobsson 1988, Hoffman 1989, Bessant 1991, Kenney and Florida 1993). We proceed to study three firms which have undergone major changes in labour productivity due to the diffusion of organisational innovations. We conclude the chapter by indicating an uneven global diffusion of organisational innovations and argue that the main effects on productivity are yet to be seen, in particular in Europe.

\subsection{New production techniques}

Industry ${ }^{7}$ is going through a whole series of changes with respect to its production techniques. Numerically controlled machine tools (NCMTs) have been extensively diffused for some time but now flexible manufacturing systems (FMSs) and robots, two additional elements of the 'factory of the future', have reached a fairly mature stage in the sense that the techniques can be usefully implemented on a large scale.

Although the first NCMT was developed in the early 1950s, the diffusion of NCMTs did not increase greatly until the second half of the 1970s. Improvements in price/performance, mainly due to advances in micro-electronics, initiated a process which led to a powerful substitution for conventional machine tools. In terms of the flow of investment in metal cutting machine tools, this substitution has already been achieved. However, the full effect on employment will be felt only in the future, as the stock of conventional machine tools is replaced by the new technology.

The first FMS was installed in 1965 in the USA. By 1970, all in all eight systems had been installed, a figure which grew to about 1,000 in 1988. In spite of its long history, FMSs have not greatly substituted for stand alone NCMTs. As far as the flow (annual additions to the stock) of FMSs is concerned, it has been estimated that approximately 4 - 5 per cent of the machining centres sold in 1988, and about 1 per cent of the $\mathrm{CNC}$ lathes, were made part of a system with two or more NCMTs (Ehrnberg and Jacobsson 1993). Clearly, FMS is only just beginning to have an impact in the market.

However, there are a set of reasons which make us believe that FMS will diffuse on a much larger scale in the 1990s (Ehrnberg and Jacobsson 1993). First, the technological change is of a character which is conducive to a wide diffusion to smaller and medium sized firms. For instance, new innovations (such as new material handling solutions and the use of micro-computers instead of mini-computers) reduce the price of FMS and allow FMS to be gradually built (for instance by adding a machine every year) instead of having a closed system architecture. Second, the major machine tool firms are now targeting these small firms. Third, these smaller and medium sized firms account for the bulk of the market for machine tools and have only begun to exploit FMS - the potential market is very large. 
Since the first robot was introduced by General Motors in 1961, robots have been greatly reduced in price, but most importantly, have improved in performance in a number of ways. New innovations have made it possible for the robot to perform more complex tasks, increasing the number of applications for which it can be used. These innovations, in parallel with the gradual performance increases and price reductions due to, for instance, continuous changes in electronics, laid part of the ground for a quite rapid diffusion of robots in the 1980s. The total stock of robots in the world grew from 21,000 in 1980 to 170,000 in 1986 and to as many as 456,000 in 1991 (Karlson 1991).

There are, furthermore, as in the case of FMS, three main reasons as to why we would expect the diffusion to continue to be high. First, technological change continuously enhances the performance of robots and increases the number of applications to which robots can be applied. One case in point is the development of vision systems which have the potential to radically change many industrial applications (Karlsson 1991), in particular assembly. Second, the leading firms are beginning to follow firm strategies which have as an objective to exploit the large potential markets outside the automobile industry and other large engineering firms. This means that prices are coming down and concerted efforts are being made to reach these new, and mainly smaller firms, with information about robots. Third, this process is aided by an accumulation of experience in society about robots. In particular, larger numbers of engineers who have a good knowledge in robotics are beginning to graduate from the Universities of Technology.

To conclude, new electronics based production technology, of which we have discussed three different forms, are now mature enough for a massive diffusion, not only among the technologically more advanced firms but also among the vast number of smaller and medium-sized firms.

\subsection{New organisational forms}

Equally important as the diffusion of new process technologies, in the sense of new hardware, is the diffusion of new organisational innovations (Alänge et al. 1993). That the effect of new technology on productivity (and quality) varies greatly depending on the choice of 'human resource system' has been shown vividly by research in e.g. the automobile industry (Osterman 1990, Womack et al. 1990) and reports are available from a set of other studies providing support for the proposition that (Osterman 1990, pp. 44-45) "... human resource policies are critical to achieving high levels of productivity and quality in manufacturing...technology alone does not drive the outcome." It has also been shown that higher levels of productivity and quality can be reached with older equipment combined with a different work organisation and a focus on continuous improvement. This was the shocking finding for Xerox Corporation when it made a direct comparison (benchmarking) with its joint-venture Fuji-Xerox, which was using Xerox's second-hand equipment in its Japanese plant .

Indeed, Hörte and Lindberg (1992) argue that, in the Swedish case, investment in new organisational forms has a higher marginal productivity than investment in new production techniques. In their study, they compared how different levels of automation and human resource management ${ }^{8}$ affected performance (as defined by productivity, quality, etc.). They suggested that improved human resource management has a more 
powerful influence on performance than acquiring more advanced technology - e.g. going from stand alone $\mathrm{NC}$ machine tools to flexible manufacturing systems. ${ }^{9}$ Clearly then, new work organisation can have a powerful effect on performance, not only as a way of utilising new production techniques better but also as an independent influence on quality and productivity.

Whilst new work organisation refers chiefly to the organisation in the machine shop, Just-in-time (JIT) is an organisational form which has repercussions throughout the firm, and on its relationships with suppliers and customers. JIT lies at the core of Japanese production management and productivity improvement (Voss 1986). It is well established among the larger Japanese firms and in recent years it has begun to be diffused in the Western countries (Bessant 1991).

Whilst the initial focus of JIT was on reducing inventories, by exposing the whole production system to the risks involved in having no buffer stocks, a whole series of additional benefits occurred. In principle, these benefits occur as working with low inventories exposes the organisation to, and demands the solution to, problems which can be hidden with large inventories.

In implementing JT programmes, three ideas are central (Bessant 1991). First, continuous improvement is sought. This reflects the view that there are no ends to the quest for excellence and that a small step forward everyday is better than a giant leap every few years. Second, problems are 'owned' jointly (i.e. problems are everybody's concern) and cannot be passed along to the next work station. Third, solving problems effectively demands the mobilization of all resources in the firm. ${ }^{10}$

JT thus requires that workers are seen as a resource who need to receive continuous training, updating of skills and respect in order for their full potential to be reaped. Developing such a highly skilled and flexible workforce also requires alternative arrangements for working practices. JT emphasises job rotation and teamwork, which provide greater variety, better motivation and an improved opportunity to 'see things with new eyes', and therefore to see the opportunity for improvement (Bessant 1991). ${ }^{11}$

New work-organisation and JIT are, however, but two elements in a new paradigm of how to manage a business. Various concepts have been used to describe this new paradigm for industrial operations that has evolved in the 1990s. The Japanese version has been called TQC (total quality control), CWQC (company wide quality control) or Toyota management system. ${ }^{12}$ Transferred to the West it is described by concepts such as "lean production", "innovation-mediated production" 13 or, maybe the most commonly used term, $\mathrm{TQM}^{14}$ (total quality management). Different authors have assigned slightly different meanings to new paradigm. This is, however, in line with reality, as companies embrace the new paradigm in slightly different ways, making it their own.

The new paradigm consists essentially of systematic management principles to make best use of all resources. The key is that the potentials of all employees should be used to achieve demanding goals, set by a committed top leadership, and built on customer 
requirements. These demanding goals, in turn, require changes in organisational and reward principles. ${ }^{15}$

The implications of this new paradigm for jobs take three routes. First, there is a qualitative change in job requirements which leads to a general upgrading of the skills, at all levels in a company. Second, through the focus on continuous improvement and on eliminating different kind of waste and rework, jobs that previously were seen as essential disappear. ${ }^{16}$ Third, the process focus in combination with policy deployment and team organisation will cut away management levels that no longer are needed, or even worse, have a tendency to prolong lead-times.

The basic idea is that everyone in a company should use his or her intelligence to the benefit of the company and take personal responsibility for quality. The organising principle which makes this workable is policy deployment and empowered teams. As Kenney and Florida (1993, p. 304) put it:

"The team is the mechanism through which workers are mobilised to solve production problems and innovate ... The team is the simultaneous source of motivation, discipline, and social control for team members, driving them to toil harder and more collectively."

The driving force for using teams is the understanding that previous industrial organisations built on functional and work task specialisation are no longer competitive, because the creative power of the employees is not unleashed. The teams may take many forms; from "QC-circles" on the shop floor, to cross-functional problem-solving teams, TPM-teams, ${ }^{17}$ which aim at improving the availability of equipment, and concurrent engineering teams composed of participants essential for product development (these teams often include suppliers and even customers).

All this means that the previous strict division of labour into white collar and blue collar becomes obsolete. ${ }^{18}$ Shop floor workers take the responsibility for planning, quality and continuous improvement activities in their work area. This changes, for example, the role of first line supervisors, who, when workers assume an increased responsibility for their work area, either have to look for a new job, or have to assume a new role and function as group process facilitators and providers of information and support to the group.

Another effect of these changes is a reduction in the number of hierarchical levels within organisations. This condition is especially evident in (a limited number of) European and US firms. ${ }^{19}$ What these pioneering Western "TQM companies" have done is to apply the techniques that the Japanese companies mastered in the production process, to administrative areas. For instance, process mapping or flow charts of administrative processes can be used to eliminate all kinds of waste or unnecessary movements, operations, paper work, documents, routines, etc. By eliminating waste, a lot of unnecessary work is also eliminated - which has considerable implications for white-collar jobs. ${ }^{20}$

All in all, a successful implementation of TQM can lead to a substantial improvement in labour productivity. Performance can be increased significantly in terms of output, 
quality and lead-time, with a constant or reduced work force, as can be seen in the following three case studies.

\subsection{Examples from the firm level}

In this section, we will illustrate the way TQM can affect employment by relating evidence from three case studies. The cases have been selected among those companies which started with TQM at an early stage and where it, hence, is possible to see clearly how employment has been affected. First, Motorola which was one of the pioneering TQM companies in the US. Second, IBM Järfalla, which was the first (1993) winner of the Swedish National Quality Award, which indicates that this company was ahead of most other Swedish companies in the development of TQM. Third, SAAB Automobile in Sweden has been through a major change programme, even taking direct assistance from Japanese advisors.

\subsubsection{Motorola}

Motorola implemented its "Total Customer Satisfaction" culture in the mid 1980s and in 1988 Motorola became the first winner of the Malcolm Baldrige National Quality Award in the USA.

By focusing on quality improvement and cycle time reduction through employee empowerment initiatives, a considerable increase in productivity was attained in 19871992. While sales increased by 128 percent, ${ }^{21}$ the number of employees increased only by $13 \%$. This means that labour productivity increased by $100 \%$ during this 5 year period (an average of $12.2 \%$ per year). Furthermore, according to Motorola's internal calculations, the quality initiative had up to 1993 saved US dollar 3.15 billion over six years (by lowering quality related costs).

These results have been accomplished through an pervasive organisational change programme led by top management. The Motorola change process includes most of the components that are seen as vital for a TQM company, such as visible leadership and clear visions and goals that are communicated all through the organisation as well as to suppliers and customers.

Motorola's goal of reaching a six sigma level for all processes in 1993, i.e. 3.4 PPM $^{22}$ (=3.4 defects per million opportunities of making an error) is known by everyone working for the company. The achieved result in 1993 was an average of 40 PPM (5.4 sigma), while many processes performed better than six sigma. This way of setting aggressive goals for defect reduction (in this case a yearly improvement of around $70 \%)^{23}$ works as a very strong motivating force to do things differently, not only working a little bit harder. As every Motorola employee can measure the development of their processes in this way, the measurement system is also a common language that can be used by all personnel at all different levels across the company.

These improvement levels could not have been reached without providing the personnel with the necessary knowledge. Hence, Motorola has been involved in a major training effort, as a start providing a general knowledge of the change programme and providing 
training in basic problem solving skills, to more specialized courses in all relevant subjects, e.g. design for manufacturing for all Motorola engineers. ${ }^{24}$ There is a minimum requirement of $40 \mathrm{hrs}$ of training per year for all Motorola employees, and the present average is closer to $80 \mathrm{hrs}$ a year.

Another essential component for empowerment has been the development of team structures for work as well as for problem solving. A suggestion system, visible recognitions, and an aligned reward system are further essential parts of the Motorola change process.

\subsubsection{IBM Järfälla}

IBM Järfälla is a production plant for printers. The plant has been transformed since 1990 through the adoption of the IBM "Market Driven Quality" (MDQ) programme, which can be seen as IBM's version of total quality management. ${ }^{25}$ The outcome of this transformation, can be seen in terms of a strong growth in labour productivity, ${ }^{26}$ i.e. keeping the production volume unchanged, the total number of employees was reduced by $35 \%$, from 1,150 to 750 , in two years.

This change in labour productivity can to a large extent be explained in terms of an organisational innovation being diffused through the IBM world-wide system. The top management of the Järfalla plant participated in training in 1990 in the MDQ programme. The company has also participated in several IBM internal audits based on the criteria in the Malcolm Baldrige National Quality Award. These audits, combined with the training, provided an understanding of process orientation in combination with aggressive goals and measurement. It, furthermore, changed the way the company was led, emphasising empowerment and team-building, as well as the need for continuing communication, through all possible means, of goals and directives as well as all relevant feedback data, to all personnel (or associates). ${ }^{27}$

\subsubsection{Saab Automobile}

After a few successful years in the mid 1980s, reinforced by a Swedish devaluation and a booming US market, Saab Automobiles found itself in a serious situation where its survival was at stake. The ownership was broadened by GM taking a 50\% share including the right to select the president. Nearly all the top management group was replaced in 1989 and a management revolution was started. Saab Automobile created its own TQM programme, QLE/H, which was greatly influenced by their Japanese competitors' success, ${ }^{28}$ but also drew on the experience of $\mathrm{GM}^{29}$ The change process was to a large extent internal and focused on both the production and product development processes.

Starting with existing products and production techniques, all processes were scrutinized and improved, in order to increase quality and productivity. In parallel, there were changes made in work organisation, establishing teams along the production line, and a measurement system for quality, lead-time and productivity was introduced where all results were communicated back to each employee. Using these measures it was possible to drastically improve an existing product which had been condemned by 
expertise, both inside and outside the company, as "hopeless to produce". From an assembly time of $110 \mathrm{hrs}$ in 1990 it has in 1994 been reduced to slightly more than 35 hrs. $^{30}$

The next step of SAAB development was concentrated on a new product where new design techniques (DFM) were applied to further lower the production time. In addition, a new production technique was developed where the advantages of the material flow to a line was kept while at the same time some of the disadvantages were designed away. ${ }^{31}$ This new product and production system allows SAAB to produce a "900 car" in $35 \mathrm{hrs}$ during the starting up phase and will most probably result in a production time below 25 hrs, when fully developed.

The management revolution has had fundamental effects on labour productivity. Whilst 88,000 cars were produced with about 10,000 employees in 1987, about the same output is achieved by less than 4,500 staff in $1994 .^{32}$

\subsection{The uneven international diffusion}

Clearly, the diffusion of new production techniques and new organisational innovations can greatly affect labour productivity and employment. The rate of increase in labour productivity, at the macro level, is though a function of the rate at which the new innovations diffuse. In this section we will examine evidence ${ }^{33}$ of the diffusion of TQM (and related innovations) and argue that as in the case of production techniques (Edquist and Jacobsson 1988), Japan has experienced a more thorough diffusion of TQM than the US and Europe. Thus, these countries have yet to experience the main effects of these new management practices.

In Japan, Just-In-Time practices spread widely in the 1970s, after the initial Toyota experiments in the 1950s and 1960s. Similarly, the principles of TQM spread quickly forming a massive movement in Japan in the 1970s and 1980s. Thus, even though some Japanese companies still have not adopted TQM and JIT, the level of diffusion of these techniques and organisational forms is very high in Japan (Nakane et al., 1992).

Europe and US experience a significant time lag as compared to Japan in the adoption of both JT and TQM. As an example, the American Malcolm Baldrige National Quality Award was introduced in 1988, long after the wide-spread use of TQM had begun in Japan. In fact, data presented by Miller et al. (1992) ${ }^{34}$ suggest that it was not until the mid 1980s that quality became a major issue in the larger US industrial companies. At that time, the quality efforts may be described as isolated activities, but after a 'quality awakening' in the mid 1980s, the American manufacturers have successively engaged in more concerted efforts towards quality management. Thus, in the first part of the 1990s, developments in larger US companies have moved from more isolated use of quality tools, to an upgrading of skills and implementation of team-based, decentralised organisations much along the lines of TQM. ${ }^{35}$

The trajectory of American industry is therefore to an increasing extent towards streamlined, 'lean' organisations, and once the knowledge of how to manage these 
changes diffuses into the bulk of American industrial companies, it is likely that overall productivity will increase greatly.

In Europe, activities in the mid 1980s in larger manufacturing companies were by and large oriented towards upgrading of hardware and techniques. Broader developments reflecting TQM principles became clearly visible only in the end of $1980 \mathrm{~s},{ }^{36}$ lagging behind the American development by a few years. ${ }^{37}$ De Meyer and Ferdows (1992) argue, however, that European firms will to an increasing extent remove "protective layers" around the manufacturing core in the 1990s. This includes reductions of e.g. inventories and management layers as well as increased cooperation with customers and suppliers. The effects of this will most likely be substantial reductions of organisational hierarchies, planning and support functions etc., as well as direct labour headcount.

The general picture of Europe's industry is therefore that it is not only lagging behind Japan but also American industry. What may be expected, therefore, is that significant productivity improvements, on a broad scale, will take place in Europe, as TQM diffuses more widely.

\section{CONSEQUENCES FOR EMPLOYMENT - A DISCUSSION}

It is clear that, for some time, we have experienced manufacturing 'growth with less jobs'. A trend shift took place in the 1980s and our argument is that this process will become accentuated in the 1990s. As described in section 3, a whole set of technical and organisational innovations are being diffused. These innovations are primarily of a rationalising type and will therefore further reduce labour input per unit of output, not always in a marginal way but frequently in a substantial way.

Of course, for the individual firms, there is no option but to follow suit if they are going to survive. However, as the technical and organisational best practices of the leading edge firms are being diffused widely, our structure of employment, and presumably society as a whole, will be greatly affected. What will come out of this process of change is not a foregone conclusion and there is certainly no consensus about how we ought to handle it.

In the following pages we will summarise some suggestions, put forward by others, of how to influence the change process.

The 'Luddite approach' simply means that the solution is seen to stop or reduce the pressure for transition by slowing down the rate of productivity growth. In 19th Century England, advocates of this approach destroyed new textile machinery which threatened thousands of textile workers' jobs (Freeman and Soete 1994).

The Greens advocate a change in the taxation system (e.g. by shifting taxes from labour to non-renewable energy sources) which may induce a greater demand for labour. Moreover, a 'greener' agricultural sector would presumably be (a great deal) more labour intensive than the presently dominating form of agriculture. 
The Job-sharers advocate a reduction in working hours and sharing of the jobs available. This has been the practice in Denmark for several years. Recently, other parts of Europe (Dagens Industri 1993), have followed through. For example, in Germany, a strong labour union (IG Metall) made an agreement on a 4 day working week with Volkswagen.

The 'Traditionalists', particularly in the Social Democratic Movement, would tend to be greatly in favour of new technology but combine its rapid diffusion with a continued high level of taxation of industry where the fruits of the productivity increases are transferred to the non-manufacturing employed chiefly via employment in the public sector. With a continued reduction in the share of manufacturing employees, this approach would involve a growing degree of taxation of these employees. Whether or not this is possible is debatable.

The Conventional economists often argue that it is not. These tend instead to argue that the private service sector needs to be expanded to absorb more of those who are not needed in the manufacturing sector (and closely linked service sectors). It is argued that it is necessary to deregulate the labour market, to reduce the unemployment benefits and to increase wage differentials. These institutional changes will then lead to an expansion in the number of low wage jobs. Hence, for us to be able to combine fast productivity growth in the manufacturing sector, and a concomitant increase in the wealth of our nations, with reasonably full employment, we need, they argue, to expand the number of people with low incomes.

The Keynesians take another standpoint and suggest measures to increase aggregate demand. A recent example of this standpoint is a Pan-European suggestion of major infrastructural investments in communication, including new information technology, launched by the former president of the European Commission, Jaques Delors (International Herald Tribune 1994). ${ }^{38}$

The 'Schumpeterians' reverse the initial argument of a negative relationship between technical change and employment and suggest that the relationship may well be positive (Freeman 1993, Metal Trades Committee 1988). Edquist (1993), for instance, points to the wide discrepancies between various countries in expanding output and employment in the 'high technology' industries. It is argued that although an expansion of these industries may not generate a great deal of extra employment, it may keep manufacturing employment levels broadly constant.

These various approaches need some further comment. First, some of them are not mutually exclusive and can, of course, be combined. Second, the particular combinations used will greatly affect how society evolves in the coming decades. For instance, if we follow the 'conventional economists' proposals, we will stand a great risk of creating a polarised society with respect to income and education. Third, in contrast to the belief of some commentators (Schuck 1994) this is not an inevitable outcome but a matter of political choice. 
We refuse, thus, to believe that we cannot 'engineer' our society so that we can reap the fruits of new technology without condemning a large fraction of the workforce to unemployment or to low paid service lobs. We believe that it is possible to find combinations of the suggestions listed above which allow us to simulteaneously achieve economic growth, high levels of employment and an equitable distribution of income. ${ }^{39}$ This is a political vision of important features of tomorrow's society. Whilst we by no means can claim to have a fully-fledged proposal, a good hypothesis is that the following components will constitute important parts of such an 'engineering design'.

A general reduction in working hours and Keynesian type policies on a European level are presumably part and parcel of a broader European strategy to combine growth with full employment. But apart from these more conventional 'components' we would like to stress three additional ones.

First, follow the advice of the 'Schumpeterians' and build a large and highly productive manufacturing sector (and associated service sectors) which excel in exploiting the present vast technological opportunities. As Freeman (1993, p. 11) points out: "economic growth is not merely accompanied by fast growing new industries and the expansion of such industries; it primarily depends on that expansion."

Autonomous investment, embodying new technical innovations, is therefore the basis for economic growth. In the process of shifting resources from existing to these new industries, a series of structural disequilibria must necessarily arise. The focus shifts then from factor price flexibility, or aggregate demand levels, to factors determining the rate of autonomous investment and eradication of structural disequilibria. This involves a whole set of policies which affect the performance of various national systems of innovation or technological systems (e.g. Freeman 1987 and 1993, Carlsson et. al. 1992, Lundvall 1993, Nelson 1993).

If successful, a Schumpeterian policy will result in a highly productive and large manufacturing sector in terms of output, although it will not generate significantly more employment opportunities. Moreover, if labour productivity increases faster in the industrial sector than in the other parts of the economy, how can "values" be transfered from this, still small sector in terms of employment, to the bulk of the work force, thus ensuring an equitable distribution of income?

For the Conventional Economists this is not seen as a problem, they simply equate marginal productivity with wage and accept the ensuing wage differentials. The Traditionalists see taxation combined with a wage policy which shows solidarity with low skilled workers as the solution. The Job-sharers and Keynesians avoid the issue by focusing on how to expand the general demand for labour. This applies, in part, to the Greens ${ }^{40}$ too whilst the Schumpeterians often include an explicit consideration of the equity problem (e.g. Freeman and Soete 1994).

We suggest, and this is the second 'component' that, together with a relatively high level of taxation, a set of avenues should be explored as a means to transfer "values" from the industrial to other sectors. This involves the development of services and agricultural products which combine three features, namely: 
* high income elasticity of demand

* high labour intensity

* high skill intensity

If such activities could be expanded, 'value' would be transferred through inter-sectoral trade combined with a favourable price ratio, which would allow for non-industrial wages which are on par with those in industry. These features prevail in industry-related services but a major task will be to expand such activities, often in a Schumpeterian way. Three obvious candidates are technology intensive education (Freeman 1993), environmentally friendly technologies, and a rapid 'greenification' of agriculture. Public policies can here play a key role by, for instance, procurement programmes, tax policy and legislation. ${ }^{4}$

Third, increase the level of ambition of the educational system by an order of magnitude. This is necessary both for reducing the structural disequilibria inherent in the process of creative destruction (and allow for higher investment levels) and for preventing the formation of an inequitable society.

It has for some time been well-known that the educational systems in Europe have not adjusted well to demands for a larger number of highly qualified engineers and scientists in new technological fields (Metal Trades Committee 1988 and 1993, EEC 1993). Obviously, the educational system needs to become more flexible and pro-active with respect to the demands inherent in the process of creative destruction (Carlsson and Jacobsson 1993). This applies, of course not only to the manufacturing sector but also to other sectors. $^{42}$

Increasing higher level education is necessary, but it is not sufficient for our vision to come true. Instead, expanding only, or mainly, higher level education would instead lead us to the inequitable world of the 'conventional economists'.

Petit (1993, p. 18) formulates this fear as follows:

"Without public policies supporting the education and training of the less skilled segments of the work force we risk to produce a society extremely polarised in terms of incomes, knowledge and job opportunities. The only alternative to unemployment for the unprivileged not belonging to the knowledge elite would be dependent, extremely low paid, trivial jobs."

A major effort is therefore required to raise the general level of education and in this process both expand the number of highly educated and make the 'distribution of education' narrower. Again, educational policy is a political choice and how we choose will greatly influence the shaping of our society. 


\section{CONCLUSIONS}

Our arguments can be summarised as a set of propositions. These propositions can, of course, be questioned and further debated. They form, however, a coherent view of the relationship between technical and organisational change and employment.

* A job-less growth pattern in the manufacturing sector in the 1970s was transformed into a pattern of growth-with-less-jobs in the 1990s.

* Due to an expected rapid diffusion of both new production technology and of new organisational forms in the 1990s, we expect that the rate of growth of labour productivity will increase in the 1990s.

* This is probably going to be most accentuated in Europe and the US which are presently lagging behind Japan in the use of both new production technology and new organisational forms.

* Unless exceptional increases in demand occur, we cannot expect manufacturing employment to increase in the 1990s.

* There is a considerable range of options and suggestions of how to handle this development with respect to both employment and income distribution.

* We suggest that it is desirable to engineer solutions which simulteaneously achieve economic growth, high levels of employment and an equitable distribution of income.

* We suggest that technical change itself will not determine the employment level, nor that neoclassical economists with their preoccupation with wage-flexibility and their dislike of equitable income distribution should be permitted to influence the income distribution effects of technical change.

* While Keynesian demand management, a reduction in working hours and a relatively high level of taxation surely need to be part and parcel of a multinational effort to increase employment and equity, we suggest that particular attention is given to the following:

- Apply a Schumpeterian approach to use more technical change to create more jobs (exploit the technological opportunities more);

- Enlarge the focus of such efforts from the manufacturing sector (and related services) to income-elastic, labour intensive and skill-intensive services and agricultural activities.

- Take a quantum leap in the education system by providing not only more tertiary education but shift the general level of education upwards by an order of magnitude. 
Through these mechanisms, we can go some way in promoting a rich and equitable society where the inherent potential of all members can be realized.

\section{REFERENCES}

S Alänge, S Jacobsson and A Jarnehammar (1993), "Some aspects of an analytical framework for studying the diffusion of organisational innovations", Dept. of Industrial Management and Economics, Chalmers University of Technology, Göteborg, to be published in Technology Analysis and Strategic Management.

S Alänge (1994), "The New Paradigm for Industrial Practices Total Quality Management 1994", CIM Working Papers, No. 1994-01, School of Technology Management and Economics, Chalmers University of Technology, Göteborg.

S Alänge and A Jarnehammar (1995), "Determinants of the diffusion of organisational innovations - the case of TQM", mimeo, Department of Industrial Management and Economics, Chalmers University of Technology, Göteborg, Sweden.

J Bessant (1991), Managing Advanced Manufacturing Technology. The Challenge of the Fifth Wave, NCC Blackwell, Manchester.

R C Camp (1989), Benchmarking: The Search for Best Practices that Lead to Superior Performance, ASQC Quality Press, Milwaukee, Wisconsin.

B Carlsson and S Jacobsson (1993), "Technological systems and development potentials - a policy analysis", mimeo, Department of Industrial Management and Economics, Chalmers University of Technology, Göteborg, Sweden and Department of Economics, Case Western Reserve University, Cleveland, USA

B Carlsson, G Eliasson, A Granberg, S Jacobsson and R Stankiewicz (1992), "Sveriges teknologiska system och framtida konkurrenskraft", Report submitted to NUTEK, 1992.

C Cooper and J Clark (1982), Employment, Economics and Technology, Wheatsheaf Books, Brighton, UK

B Creech (1994), The Five Pillars of TQM - How to Make Total Quality Management Work for You, Truman Talley/Dutton, New York.

Dagens Industri (1993), "Arbetslösheten kan bli kronisk - Barnevik förutser lång kris for sysselsättningen", Dagens Industri, Monday, February 1.

Dagens Industri (1995), "Moder Svea byter kostym", Dagens Industri, Wednesday; May 31. 
T H Davenport (1993), Process Innovation - Reengineering Work through Information Technology, Harvard Business School Press, Boston.

A De Meyer and K Ferdows (1992), "The Europe report: Removing the barriers in manufacturing", in Miller, J.G., De Meyer, A. and Nakane, J., Benchmarking Global Manufacturing, Business One Irwin, Homewood

C Edquist (1993), "Technological Unemployment and Innovation Policy in a Small Open Economy", paper presented to the Conference on Technology, Innovation Policy and Employment, organised by the OECD and the Finnish Government, 7-9 October 1993, Helsinki.

C Edquist and S Jacobsson (1988), Flexible Automation. The global diffusion of new technology in the engineering industry, Basil Blackwell, Oxford.

EEC (1993), "Growth, Competitiveness, Employment. The Challenges and Ways Forward", in the 21st Century, White Paper, Brussels.

E Ehrnberg and S Jacobsson (1993), "Technological discontinuity and competitive strategy - Revival through FMS for the European Machine Tool Industry?", in Technological Forecasting and Social Change, 44, pp 27-48.

C Freeman and L Soete (1994), Work for all or Mass Unemployment, Pinter Publishers, London.

C Freeman (1977), "Technical change and unemployment", paper presented at the conference on 'Science, Technology and Public Policy - an International perspective', 12 December (Kensington, University of New South Wales).

C Freeman (1987), Technology and Economic Performance: Lessons from Japan, Pinter Publishers, London.

C Freeman (1993), "Technical Change and Unemployment: the Links between Macroeconomic Policy and Innovation Policy", paper presented to the Conference on Technology, Innovation Policy and Employment, organised by the OECD and the Finnish Government, 79 October 1993, Helsinki.

L W Foster (undated), "Lessons form NUMMI: The General Motors - Toyota Joint Venture Operation", The University of Alabama, Tuscaloosa. (mimeo)

K Hoffman (1989), "Technological Advance and Organisational Innovation in the Engineering Industry - A new perspective on the problems and possibilities of developing countries", Industry and Energy Department Working Paper, Industry Series Paper, No. 4, World Bank

S Å Hörte and P Lindberg (1992), "Performance effects of Human and Technological Development", Working Paper, Arbetsvetenskapliga Kollegiet, Göteborg. 
International Herald Tribune (1994), "Retooling the European Work Hours Produces No Miracle", International Herald Tribune, March 10, 1994, p.13.

K Ishikawa (1985), What is Total Quality Control - The Japanese Way, Prentice Hall, New York.

S Jacobsson, C Oskarsson, and J Philipsson (1993), "Sweden's scientific and technological profile. How do we measure it and what does it look like?", mimeo, Department of Industrial Management and Economics, Chalmers University of Technology, Göteborg, Sweden.

JUSE (1987), "Features of Company-Wide quality Control in Japan", by T Ikezawa, Y Kondo, A Harada and T Yoneyama, Proceedings form the International Conference on Quality Control (ICOC) in Tokyo 1987, pp. 43-47.

J Karlsson (1991), A decade of Robotics, Mekanförbundets Förlag, Stockholm.

D T Kearns and D A Nadler (1992), Prophets in the Dark - How Xerox Reinvented Itself and Beat Back the Japanese, Harper Business, New York.

M Kenney and R Florida (1993), Beyond Mass Production The Japanese System and Its Transfer to the US, Oxford University Press, New York.

P Lillrank (1993), "Social preconditions for lean management and its further development", Working Paper, Stockholm School of Economics, Stockholm.

P Lillrank (1994), personal communication

B Å Lundvall (editor) (1992), National Systems of Innovation.. Towards a Theory of Innovation and Interactive Learning, Francis Pinter, London.

Metal Trades Committee (1988), "Productivity and new production processes in the metal trades and their effect on employment and conditions of employment", Report II, International Labour Office, Geneva.

Metal Trades Committee (1993), "Consequences of structural adjustment for employment, training, further training and retraining in the metal trades", Report II, International Labour Office, Geneva.

J G Miller, A De Meyer and J Nakane (1992), Benchmarking Global Manufacturing, Business One Irwin, Homewood.

J Nakane, S Kurosu and H Matsuura (1992), "Creating Customer Driven Flexibility: Executive Summary of the 1990 Japanese Manufacturing Futures Survey", in J G Miller, A De Meyer and J Nakane, Benchmarking Global Manufacturing, Business One Irwin, Homewood. 
R R Nelson (editor) (1993), National Innovation Systems - A comparative analysis, Oxford University Press, New York.

Y Monden (1993), Toyota Management System - Linking the Seven Key Functional Areas, Productivity Press, Cambridge, MA

P Osterman (1990), "New Technology and Work Organisation", in E Deiaco, E Hörnell and G Vickery (editors), Technology and Investment. Crucial issues for the 1990s, Francis Pinter, London.

L Palmer, C Edquist and S Jacobsson (1984), "Perspectives on technical change and employment", Discussion paper no. 167, Research Policy Institute, University of Lund, Sweden.

P Petit (1993), “Technology and Employment: Main Issues in a Context of High Unemployment", paper presented to the Conference on Technology, Innovation Policy and Employment, organised by the OECD and the Finnish Government, 7-9 October 1993, Helsinki.

J Schuck (1994), "Bråttom stävja arbetslösheten”, Dagens Industri, February 18th 1994.

C A Voss (1986), Managing new manufacturing technologies, OMA, Monograph 1, Graduate School of Business Administration, Michigan State University.

S Watanabe (1987), Microelectronics. automation and employment in the automobile industry, John Wiley, Chichester.

J P Womack, D T Jones and D Roos (1990), The Machine that Changed the World - the story of lean production, MacMillan, New York. 


\section{Notes}

1 The inspiration for this paper was a request from the ILO to provide part of a background paper (Metal Trades Committee, 1993) for the Thirteenth Session of the Metal Trades Committee, Geneva, 1994. We are grateful to Gijsbert van Liemt for useful discussions around our (Alänge \& Jacobsson) report to the ILO. The present paper is an extension of our report, with the addition, inter alla, of Dr. Lindbergh's experiences from the Global Manufacturing Futures project, see section 3.4. Mr. T. Yamada of UNIDO kindly helped us with the data input for Figure 1 and Table 1.

${ }^{2}$ Dagens Industri (1993).

3 The postulated relationship between technical change and employment is here positive.

4 Exogenous factors in the realm of macro-economics can also affect the degree to which an initial job displacement is compensated for.

${ }^{5}$ Due, for instance to a varying strength in the inter-sectoral links and in the ability to move into new processes and product areas, we would expect that the patterns of output, employment and productivity will vary between countries. For instance, Japan increased its manufacturing employment in the period 1963-1990 with eleven per cent in spite of a growth in labour productivity of 338 per cent. Sweden, on the other hand, reduced employment with 16 per cent in spite of achieving a growth in labour productivity of only 124 per cent (Elaboration on data supplied by UNIDO).

${ }^{6}$ The observed tendency in our data is further supported by more recent OECD data, which indicates that while average industrial employment in 18 OECD countries has decreased by $12 \%$ between 1990-1994, the industrial output has remained constant (Dagens Industri, 1995).

${ }^{7}$ The examples of new production techniques are drawn mainly from the engineering industry (ISIC 38) which, however, accounts for approximately 40 per cent of industrial value added in many developed countries.

${ }^{8}$ Hörte and Lindberg (1992, p. 9) identified five levels of human resource management: 1) Taylorism, individual jobs, hierarchical organisation. 2) Group org. with centralized responsibility for quality, planning, costs, etc. (i.e. staff higher up in the hierarchy has the responsibility for this). 3) Flow-groups with responsibility for simpler planning, etc. 4) Integrated flow groups with responsibility for recruitment, quality, planning, etc. Simple, continuous training. 5) As 4, with responsibility for contacts, personnel development, economy. Advanced training.

There is ample evidence from other studies to support this notion, e.g. the limited impact of GM's heavy investment in automation under former CEO Roger Smith, while at the same time the use of a new work organisation in the Nummi Plant (a GM-Toyota joint-venture) brought considerable improvements in quality and productivity, i.e. a new management with basically the same work force in an old GM plant in Freemont, California (Womack et al. 1990 and Foster, undated).

${ }^{10}$ Here, we connect back to the idea of more progressive human resource management discussed above. As Bessant (1991, p.200, 217) puts it: 'The basis for this /participation/ is the belief that, contrary to Taylor's theory, specialist functions do not have monopoly on good ideas...JIT requires a high degree of flexibility in working practices to ensure that there are the necessary skills where and when they are needed - just in time for them to be used...it requires that workers are trained to be multifunctional, able to carry out a variety of tasks and to switch quickly between them".

11 Simply providing greater variety does not ensure that the required skill level is higher. The greater variety may still cover a very limited range of movements/actions. The greater variety should be combined with multi-skilling to be really effective.

12 Ischikawa (1985), JUSE (1987), Monden (1993).

13 Womack et al. (1990), Kenney \& Florida (1993).

14 E.g. Creech (1994).

15 Typical features of TQM are: customer focus, visible and committed leadership, clear communications of visions and goals, expectations of non-marginal rates of improvement, simple measurements of progress which are understood by all employees, multi-faceted reward system where recognition is a key feature, empowerment of all employees in a company through upgrading of skills and decentralisation of decision making, extensive use of small group activities, process-view and JIT-systems, and continuous learning, including benchmarking.

${ }^{16}$ Jobs that fall into this category are: inspection, rework to correct defect products, etc.

17 TPM = Total Productive Maintenance.

18 ".. we expect the eventual rise of new forms of worker organisations that go beyond the conventional mass-production unions ... unions will have to devise new strategies that are in line with the new model - 
for example, organising researchers, engineers, and shop-floor workers .." (Kenney \& Florida 1993, p. 305).

${ }^{19}$ However, the same is not the case in Japanese firms, where even leading companies such as Toyota, are struggling with more bureaucratic administrative structures that have shown to be difficult to change due to a number of reasons, e.g. life-time employment (Lillrank 1994).

${ }^{20}$ Process mapping also forms the basis for "benchmarking", which according to Camp (1989) aims at comparing all kinds of processes to best practices found: internally, by a direct competitor, by industry leaders (in other industries) or in generic processes. Furthermore, process analysis in combination with new information technology has a potential of creating leaps in labour productivity, through

reengineering of processes (Davenport 1993).

${ }^{21}$ In terms of dollars it was increased from 7.5 to 17 billon dollars in 1993 (in nominal prices).

${ }^{22} \mathrm{PPM}=$ parts per million.

${ }^{23}$ Similarly, the lead time reduction in manufacturing has been reduced from weeks to hours. Also in administrative areas the lead time reduction has been substantial, e.g. $75 \%$ time reduction in order processing, $66 \%$ time reduction in corporate-wide financial closing.

${ }^{24}$ The DFM course was provided to all 15.000 design engineers through a cascading principle, where the managers first learned and then trained their own personnel.

${ }^{25}$ IBM's MDQ program to a large extent builds on Motorola's experiences and uses a similar set of major goals for transformation, e.g. quality improvement and lead time reduction.

${ }^{26}$ IBM Järfälla has reached a world class productivity level, which is indicated by the fact that the plant has received the sole supplier status for two different printers, in world-wide competition with IBM's other production plants.

${ }^{27}$ This includes breakfast meetings with associates and the plant manager, regular info meetings with all associates, monthly product quality review meetings, and the MDQ-council where the whole leadership group is represented.

${ }^{28}$ In the press-shop, a Japanese company has been instrumental in developing up-to-date tool change and set-up procedures, combined with continuous improvement practice (Kaizen). The increased participation of the employees in improvement activities can be seen in the development of the suggestion statistics, from around 700 suggestions in the mid 80's to 22,000 suggestions in 1994, which means that SAAB is in the top group of Swedish companies.

${ }^{29}$ One example is the supply management including direct "Kaizen" intervention in the suppliers production facilities through "Picos"-teams, in order to eliminate waste, cut lead time and cost to the supplier to the benefit of both Saab and the supplier.

${ }^{30}$ The Saab productivity was initially one of the worst in industry, using $110 \mathrm{hrs}$ to produce a car while the best Japanese competitors used 16 hrs to assemble a car (Womack et al. 1990).

${ }^{31}$ This is done by letting the car body hang on a "tipping" conveyor, which allows healthy work positions, and by letting the assembly workers stand on a moving floor which moves at the same speed as the car body on the conveyor.

32 A minor part of the reduction of employment is due to that SAAB has sold some units making components to outside companies.

${ }^{33}$ While there are several studies examining the diffusion of production techniques (e.g. Edquist and Jacobsson, 1988), corresponding studies of the diffusion of organisational innovations are still lacking. However, for the purpose of this article, there are some international studies on manufacturing strategy that allow us to generate conclusions on the trends in organisational development in Japan, the US and Europe during the last decade. We will chiefly refer to data from the "Global Manufacturing Futures" project initiated in Boston in 1981 (see e.g. Miller et al., 1992)

${ }^{34}$ Data is from the Global Manufacturing Futures project 51. Interpretations of data from Miller and Kim (1990).

${ }^{35}$ Interpretations of data from Miller and Kim (1990).

${ }^{36}$ According to Miller et al. (1992) manufacturing action plans in larger European manufacturing companies were in 1986 (in order of importance): Lead-time reduction, Production and Inventory control, Information systems, Worker motivation and Mechanisation, while the action plans in 1989 had turned to Zero Defects, Vendor Quality, Information systems, Worker training and Automation.

${ }^{37}$ There are of course individual exceptions among Europe's industrial firms, e.g. ABB is seen as an international benchmark for a decentralised and "lean" organisational structure.

${ }^{38}$ "The hit parade of favorite solutions to Europe's unemployment crisis includes several remedies, but as a white paper prepared by the president of the European Commission admits, there is no miracle cure. 
The plan prepared by Jacques Delors is itself a smorgosbord of ideas, ranging from the need to stimulate growth to the idea of trans-European infrastructure networks in transport, energy and information technology. These would be made attractive investment opportunities by virtue of accelerating administrative procedures. The white paper also focuses on the need to make the labor market more flexible, on improving training and education, and on tackling the non-wage labor costs, high even for unskilled workers and which discourage creation of low-wage jobs in the service sector" (International Herald Tribune 1994).

${ }^{39}$ This does not contradict the view of a gradual income development based on a person's life cycle. A lower initial salary (possibly for apprentice positions) which grows with experience, multi-skill acquisition and increased responsibilities, may in several aspects function as a motivator towards personal growth.

${ }^{40}$ The Greens' doubts of the ecological basis for a continued high growth suggests that the growth of the manufacturing industry needs to consider ecological restrictions to a degree which so far is far from attained.

${ }^{41}$ There is no reason for expecting new organisational forms to be applied only in the manufacturing sector. Not only are they expected to be diffused to the industry-related services (and to the candidates for expansion of employment noted above) but also to the public sector (see Alänge and Jarnehammar 1995 for a study of the diffusion of TQM to and in a hospital). As this diffusion progresses, the discrepancy in labour productivity will decline but at the expense of a number of employment opportunities. This means that a greater weight has to be given to the propositions of the Job-sharers and the Keynesians.

${ }^{42}$ Indeed, in the Swedish case, industry related services have a larger number of scientists and engineers employed than the manufacturing sector proper (Jacobsson et al. 1993). 
SUMEP.XLC

Production vs Employment 1963 - 1990, Developed Countries (Manufacturing Sector, ISIC 300)

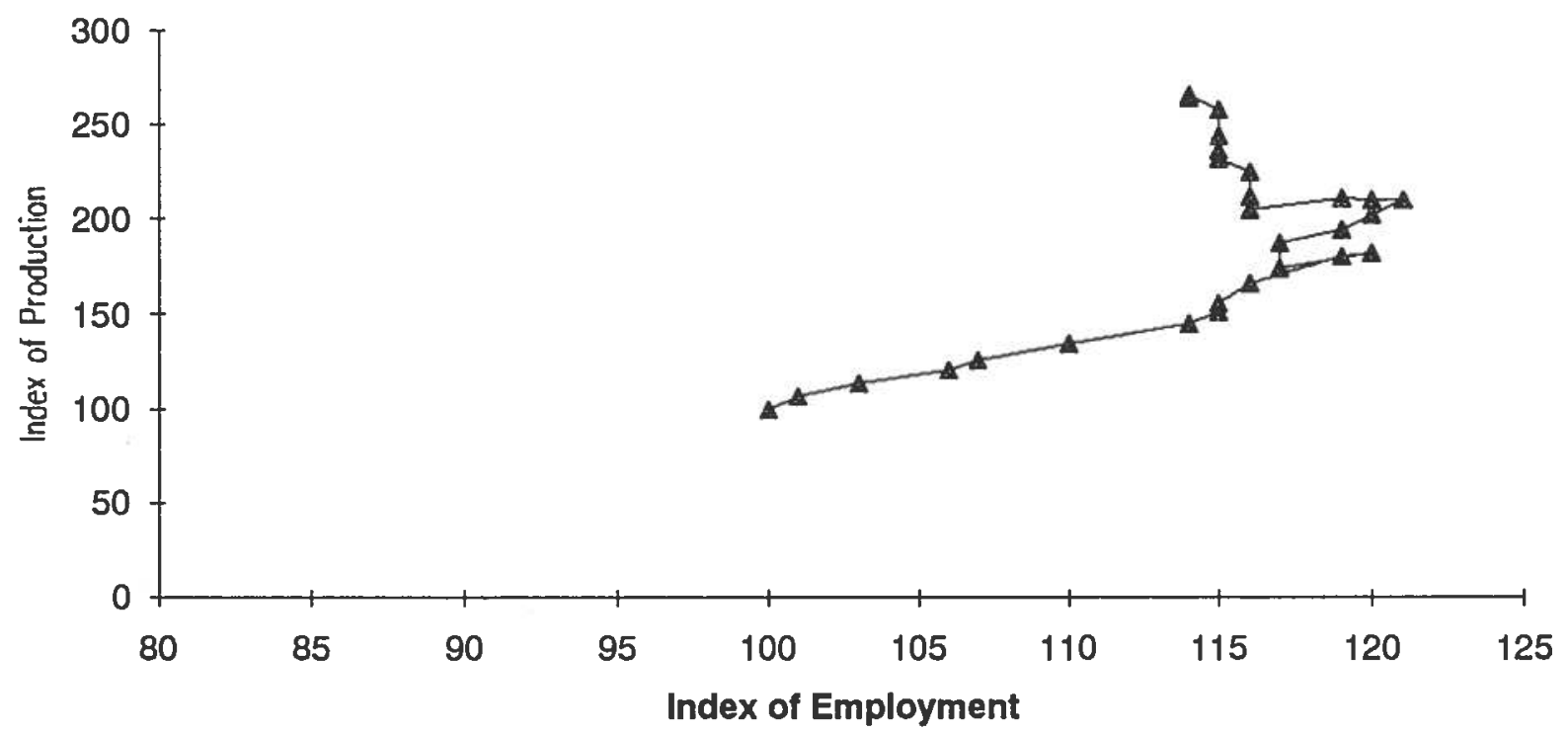

Page 1 